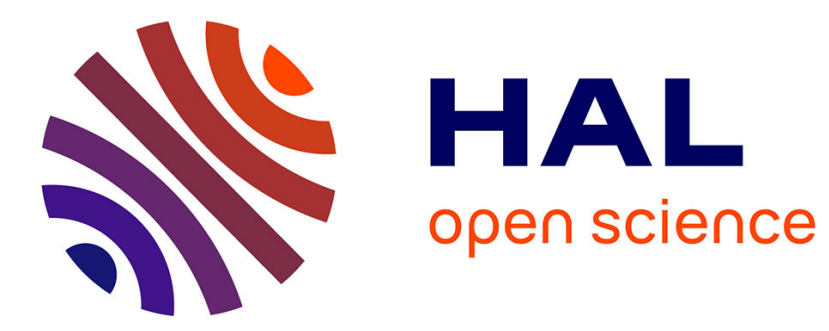

\title{
Is nasal carriage of the main acquisition pathway for surgical-site infection in orthopaedic surgery?
}

P. Berthelot, F. Grattard, C. Cazorla, J.-P. Passot, J.-P. Fayard, R. Meley, J. Bejuy, F. Farizon, B. Pozzetto, F. Lucht

\section{- To cite this version:}

P. Berthelot, F. Grattard, C. Cazorla, J.-P. Passot, J.-P. Fayard, et al.. Is nasal carriage of the main acquisition pathway for surgical-site infection in orthopaedic surgery?. European Journal of Clinical Microbiology and Infectious Diseases, 2010, 29 (4), pp.373-382. 10.1007/s10096-009-0867-5 . hal-00568345

\section{HAL Id: hal-00568345 \\ https://hal.science/hal-00568345}

Submitted on 23 Feb 2011

HAL is a multi-disciplinary open access archive for the deposit and dissemination of scientific research documents, whether they are published or not. The documents may come from teaching and research institutions in France or abroad, or from public or private research centers.
L'archive ouverte pluridisciplinaire HAL, est destinée au dépôt et à la diffusion de documents scientifiques de niveau recherche, publiés ou non, émanant des établissements d'enseignement et de recherche français ou étrangers, des laboratoires publics ou privés. 
Diseases

Editorial Manager(tm) for European Journal of Clinical Microbiology \& Infectious Manuscript Draft

Manuscript Number: EJCMID-D-09-00479R1

Title: Is nasal carriage of Staphylococcus aureus the main acquisition pathway for surgical-site infection in orthopaedic surgery?

Article Type: Article

Keywords: Staphylococcus aureus; nasal carriage; carrier; surgical site infection; hospital infection; orthopaedic surgery

Corresponding Author: Pr Philippe Berthelot, PhD, MPH, MD

Corresponding Author's Institution: University hospital of Saint-Etienne

First Author: Philippe Berthelot, PhD, MPH, MD

Order of Authors: Philippe Berthelot, PhD, MPH, MD; Florence Grattard, MD, PhD; Celine Cazorla, MD; Jean Paul Passot, MD; Jean Philippe Fayard, MD; Roland Meley, MD; Jacques Bejuy, MD; Frederic Farizon, MD; Bruno Pozzetto, MD, PhD; Frederic Lucht, MD

Abstract: Purpose

The endogenous or exogenous origin of Staphylococcus aureus, responsible for orthopaedic surgical site infections (SSI), remains debated.

Methods

We conducted a multicentre prospective cohort study to analyse the respective part of exogenous contamination and endogenous self-inoculation by S. aureus during elective orthopaedic surgery. The nose of each consecutive patient was sampled before surgery. Strains of S. aureus isolated from the nose and the wound, in case of SSI, were compared by antibiotypes or pulsed field gel electrophoresis (PFGE).

Results 3908 consecutive patients undergoing orthopaedic surgery were included. Seventy seven patients developed an SSI (2\%), including 22 related to S. aureus $(0.6 \%)$. S. aureus was isolated from the nose of 790 patients $(20.2 \%)$ at the time of surgery. In multivariate analysis, S. aureus nasal carriage was found as a risk factor for S. aureus SSI in orthopaedic surgery. However, only 9 subjects exhibiting S. aureus SSI had been found carriers before surgery: when compared, 3 pairs of strains were considered different and 6 similar.

Conclusion

In most cases of S. aureus SSI, either an endogenous origin could not be demonstrated, or pre-operative nasal colonisation retrieved a strain different from the one recovered from the surgical site

Response to Reviewers: Reply to reviewers

Thank you for these interesting comments. Please find below our answers to the queries of the two reviewers.

\section{Reviewer 1}


It is unfortunate that they did not screen other sites such as the throat and perineum.

We agree with this comment. Initially, the protocol included a rectal swabbing but many patients were reluctant to this proposal. Due to a high rate of missing data during the initial step of the study, we decided to stop the sampling of this site. The following sentence was added in the discussion section of the new manuscript (page 11; lines 12 to 14): "Our protocol included initially a rectal swabbing before surgery; however, since many patients denied this sample, the data regarding rectal specimens could not be taken into consideration". Concerning the throat sampling, when the study was designed in 2002 , sampling this site was not recommended since this specimen was not considered at this time to increase significantly the sensitivity of the recovery of S. aureus from the upper respiratory tract as shown later by Metz et al. in 2007 [ref 23] (this point is discussed page 11, lines 14 to 17).

They could point out that sole carriage at these sites is rare (perhaps 10\%) and add this to their estimates of the possible size of the problem (20\% larger!). Nasal carriage rather than carriage should be in the text.

We also agree with this comment, which is emphasised in the new discussion section (page 11; lines 14 to 17): "With a single nasal sample and in the absence of additional throat and rectal specimens, the frequency of carriage of S. aureus in our cohort was certainly underestimated, as illustrated by the figure of $20.2 \%$ of nasal carriers in this study compared to $37.1 \%$ in the one of Mertz et al [23] that combined nasal and throat samplings."

Comment 1 about CNS data:

1) Table 3 has overall data. They could compare the antibiograms of the individual isolates and see if there are very different strains. I doubt the organisms are available for molecular analysis (if so this could be "future work" for the discussion) but at least the antibiograms could be compared by ward and centre and see if there are any similarities and differences and informed guesses made as to the likelihood of cross infection e.g. quinolone resistance is usually mutational

2) All the other infected organism data. Again what about antibiograms and possible cross infection?

The goal of the study was to address the potential link between S. aureus nasal carriage and occurrence of S. aureus SSI, and not to study CNS or other bacterial cross infections. Strains other than S. aureus were not kept for further analysis. By contrast, the potentiality of cross infections with S. aureus was investigated and presented with some details in the revised manuscript (see below).

3) $\mathrm{S}$ aureus data.

We need to see their rule set for deciding why the extra 5 strains were different or similar. This is a difficult area and must be explained.

The way used to compare antibiotypes is reported in the method section (page 6, lines 12 to 16). As required by the referee, additional information regarding the comparison of antibiotic profiles has been added in the footnotes of Table III.

They should compare the 13 SA from non carriers (and indeed the carriers) to see if there are possible issues of cross infection in terms of time person and place of the affected patients. Are these strains similar by PFGE? Are they similar to any of the carriers? 
From the 13 S. aureus SSI strains isolated from non nasal carriers, 8 were available for comparison by PFGE: all these strains exhibited independent profiles, also different from those of strains isolated from the nose of colonised patients. The 5 remaining strains were isolated from non nasal carriers hospitalized in 5 different centres, excluding cross transmission. These data were added in the result section page 9 lines 10 to 13 .

Table IV only has death related risk analysis not as stated on page 10 lines 23-24 for SSI and SA nasal carriage.

Because of the low number of SSI infections, the multivariate analysis was run with a maximum of 3 covariates selected among the most significant in the univariate analyses. This sentence was added in the method section (page 8 lines 8 to 10). We also modified the sentence presenting Table IV (page 10 lines 14 to 15$)$.

4) There are also the therapeutic issues raised by the AST results for all categories of infections above. These are perhaps a little peripheral but I think it would add to the paper or perhaps be another one if there are clinical outcome data?

Data regarding therapeutic issues are not presented in this paper. Another clinical paper focusing on these results is in preparation

Other points

How were nasal swabs taken: were the swabs moistened?

The precision regarding moistened transport medium was added in the method section (page 5, line 1).

Was the PFGE protocol validated to be able to distinguish strains and how?

The criteria for PFGE interpretation are described page 6 lines 10 to 12 "For a same patient, according to Tenover's criteria [18], two S. aureus strains were classified as epidemiologically distinct if a difference of more than three bands was ascertained between the PFGE profiles performed in a same run".

\section{Reviewer 2}

First this was a multicenter study and in these kind of studies cluster effects may occur. In the multivariate analysis, adjustment for cluster effects was not included. This would strengthen the conclusions.

As pointed by the reviewer it is important to look for cluster effect. This was investigated by adding a "centre" variable in the different statistical analyses. This variable did not remain in the final model used for multivariate analysis. But as required by the referee, we performed another multivariate analysis using windows $S A S \circledR 9.1$ software to adjust for cluster effect. This was added in the method section (page 7, line 25). We replaced the results of the previous multivariate analysis performed using SPSS software by the results of this multivariate analysis adjusted for cluster effect (Table IV). 
Second, the authors conclude that the majority of the S. aureus strains are of exogenous origin. They put it quite strong in the conclusions that 'at least 16 were not endogenous'. In my opinion this is not correct. The nasal cultures were negative but this may have been a false-negative result, e.g. due to the sampling technique. As the carriage rate was only $20 \%$ it is clear that the culture technique was not very sensitive (normally $30 \%$ of the population is nasal carrier). Therefore, I suggest to modify this conclusion.

In the majority of cases an endogenous origin could not be demonstrated would be more correct.

We agree with this comment. The discussion section was amended accordingly (see answer to reviewer 1 and additional sentence in page 11; lines 14 to 17)).

As suggested by the referee, we also modified the conclusion; the sentence "In most cases of S. aureus SSI, pre-operative nasal colonization was not documented or retrieved a different strain from the infecting pathogen" was replaced by the following one in the new manuscript (page 12, lines 20 to 22 and in the abstract): "In most cases of S. aureus SSI, either an endogenous origin could not be demonstrated, or pre-operative nasal colonisation retrieved a strain different from the one recovered from the surgical site"

Also, it would be important to provide information on the typing of the strains from non-carriers as well. I wonder whether there were many similar strains within centers suggesting a common source?

This point was also addressed by reviewer 1 . No cross transmission of $\mathrm{S}$. aureus was documented in this cohort. This important point was added in the result and discussion section, page 9 lines 10 to 13 . The following sentence was added page 12 line 11 to 12 "It is noteworthy that, in our study, no cross transmission of S. aureus within centres was documented". 


\section{Figure 1:}

$(100 \%)$ 4046

$(98.0 \%)$

$(96.6 \%)$

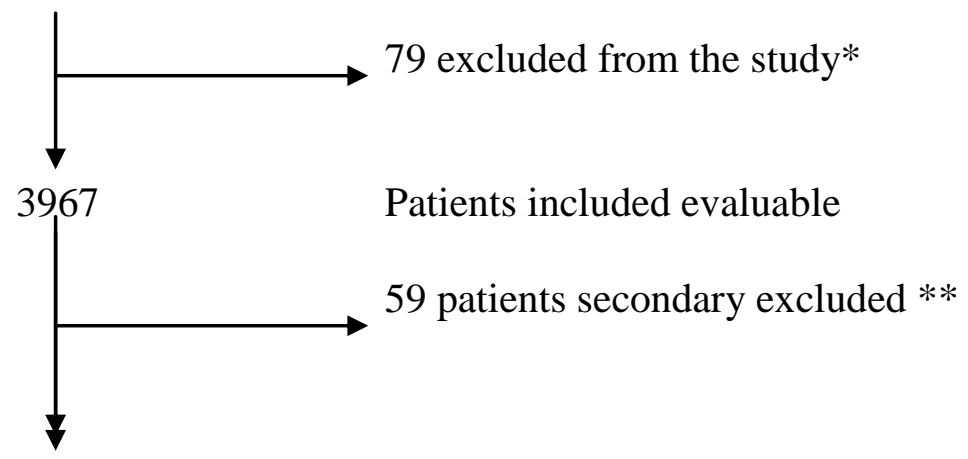

3908

Patients evaluated
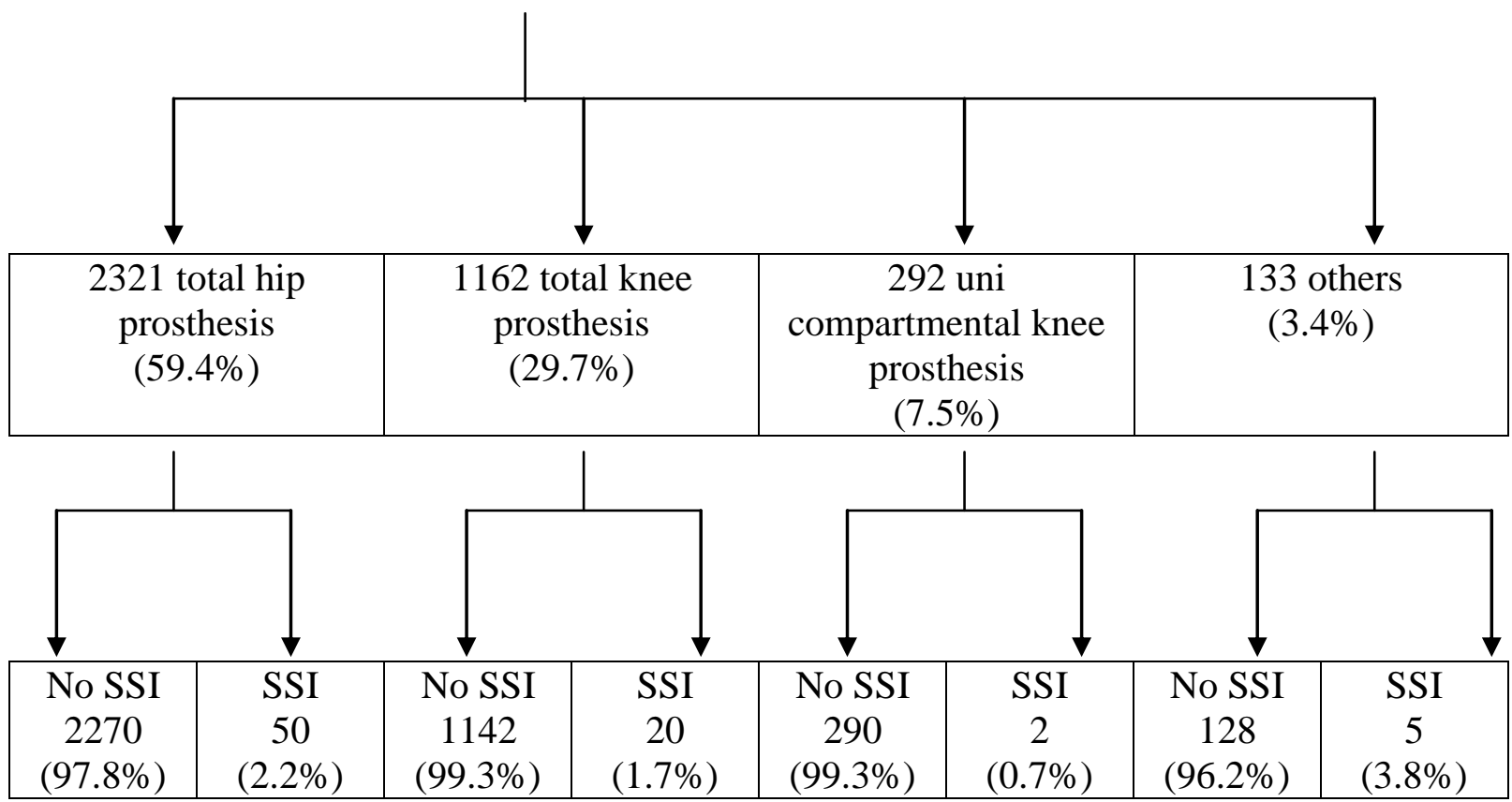

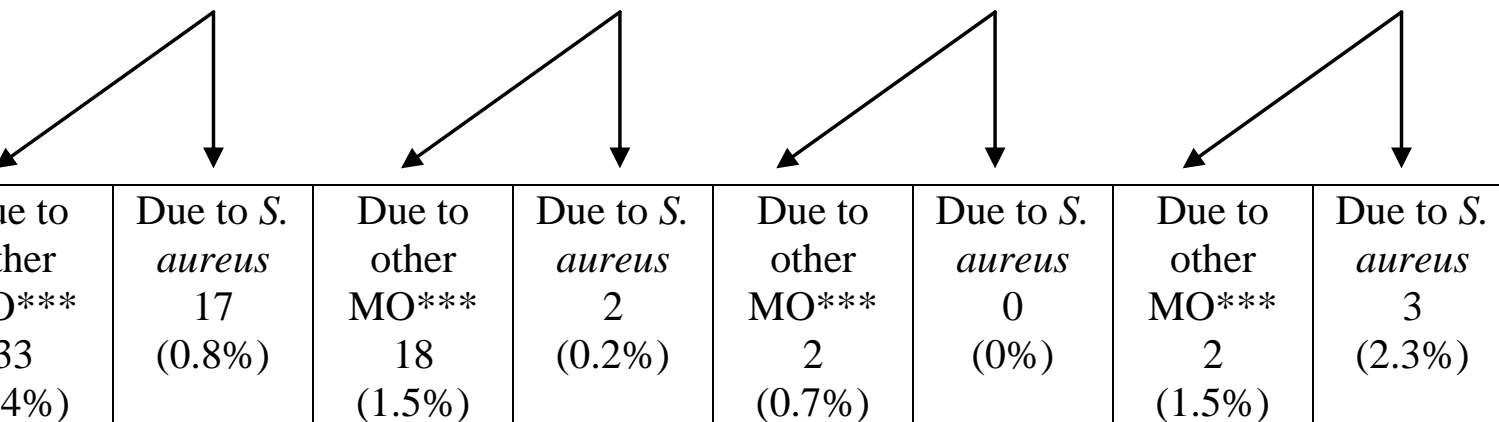

* 2 suspicions of prosthesis infection, 4 other foreign materials, 2 canceled surgeries, 1 other surgery, 1 hip prosthesis luxation, 1 without clinical data. The remaining patients had no nasal sampling

** no clinical data $(\mathrm{n}=18)$ or no nasal sampling $(\mathrm{n}=41)$

*** MO: micro-organisms 
Figure 2:

Patient

$\begin{array}{llll}15 & 1 & 22 & 12\end{array}$

Isolate

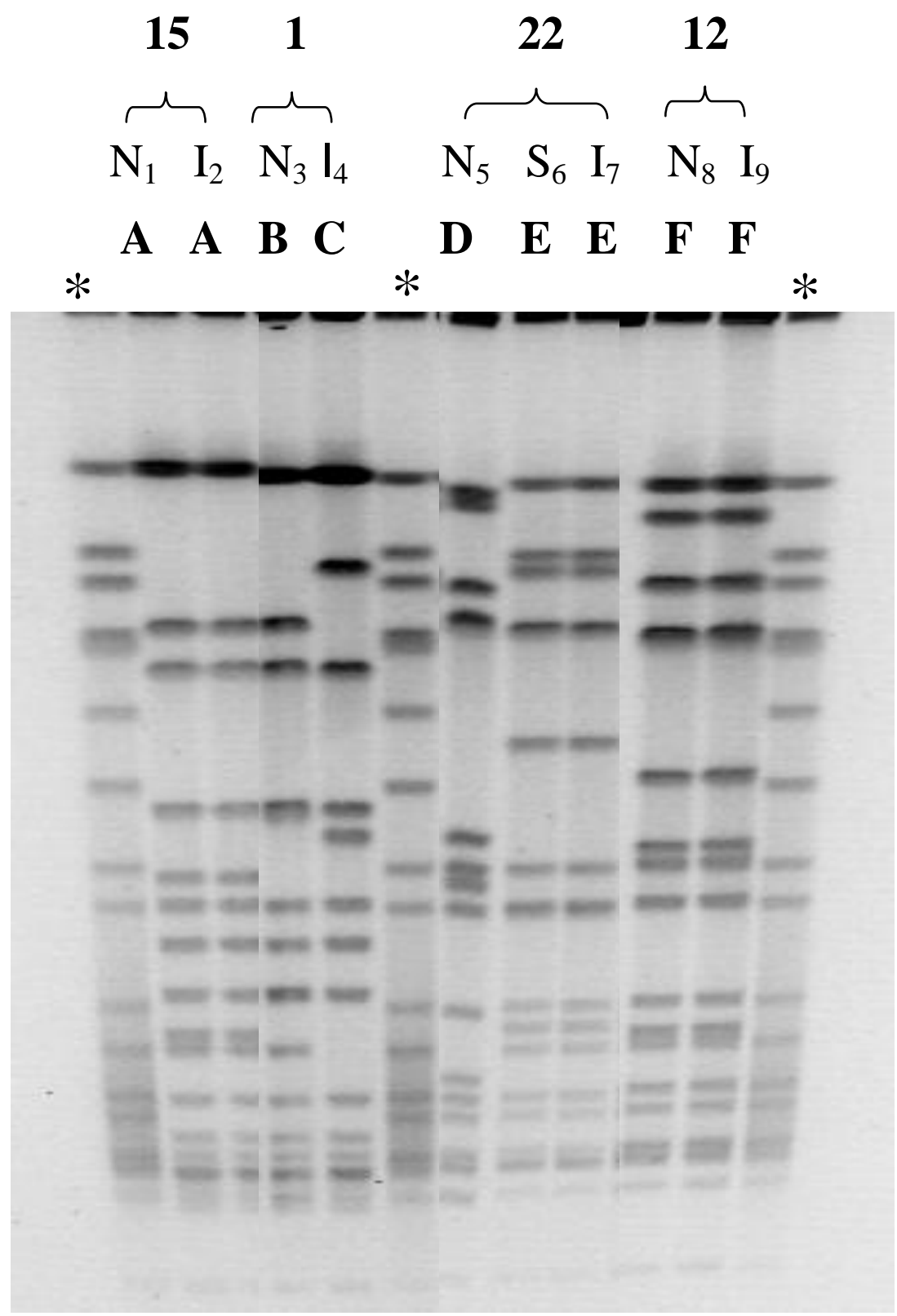




\section{Is nasal carriage of Staphylococcus aureus the main acquisition}

\section{2 pathway for surgical-site infection in orthopaedic surgery?}

3 Philippe Berthelot, Florence Grattard, Celine Cazorla, Jean-Paul Passot, Jean-Philippe

4 Fayard, Roland Meley, Jacques Bejuy, Frederic Farizon, Bruno Pozzetto, Frederic Lucht.

5 University Hospital and University Jean Monnet, Saint Etienne-France (P. Berthelot MD MPH PhD, F.

6 Grattard MD PhD, C. Cazorla MD, F. Farizon MD, B. Pozzetto MD PhD, F. Lucht MD)

7 Group "Mucosal immunity and Pathogen Agents" University Jean Monnet, Saint Etienne-France (P.

8 Berthelot, F. Grattard, C. Cazorla, B. Pozzetto, F. Lucht)

9 Clinique Mutualiste, Saint Etienne-France (JP Passot MD, JP Fayard MD, R Meley MD)

10 University Hospital, Lyon- France (J. Bejuy MD)

CHU Saint Etienne Cedex 02, France

Fax: +33477127824

Tel: +33477127726

philippe.berthelot@chu-st-etienne.fr

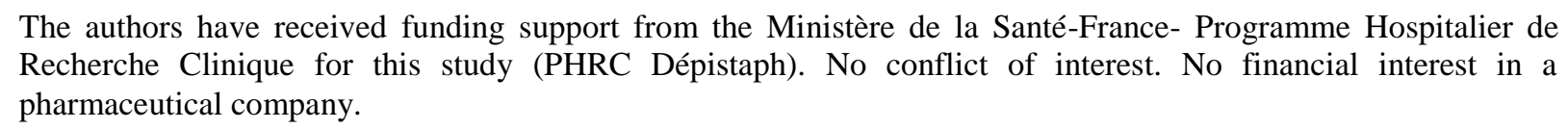
Recherche Clinique for this study (PHRC Dépistaph). No conflict of interest. No financial interest in a pharmaceutical company. 


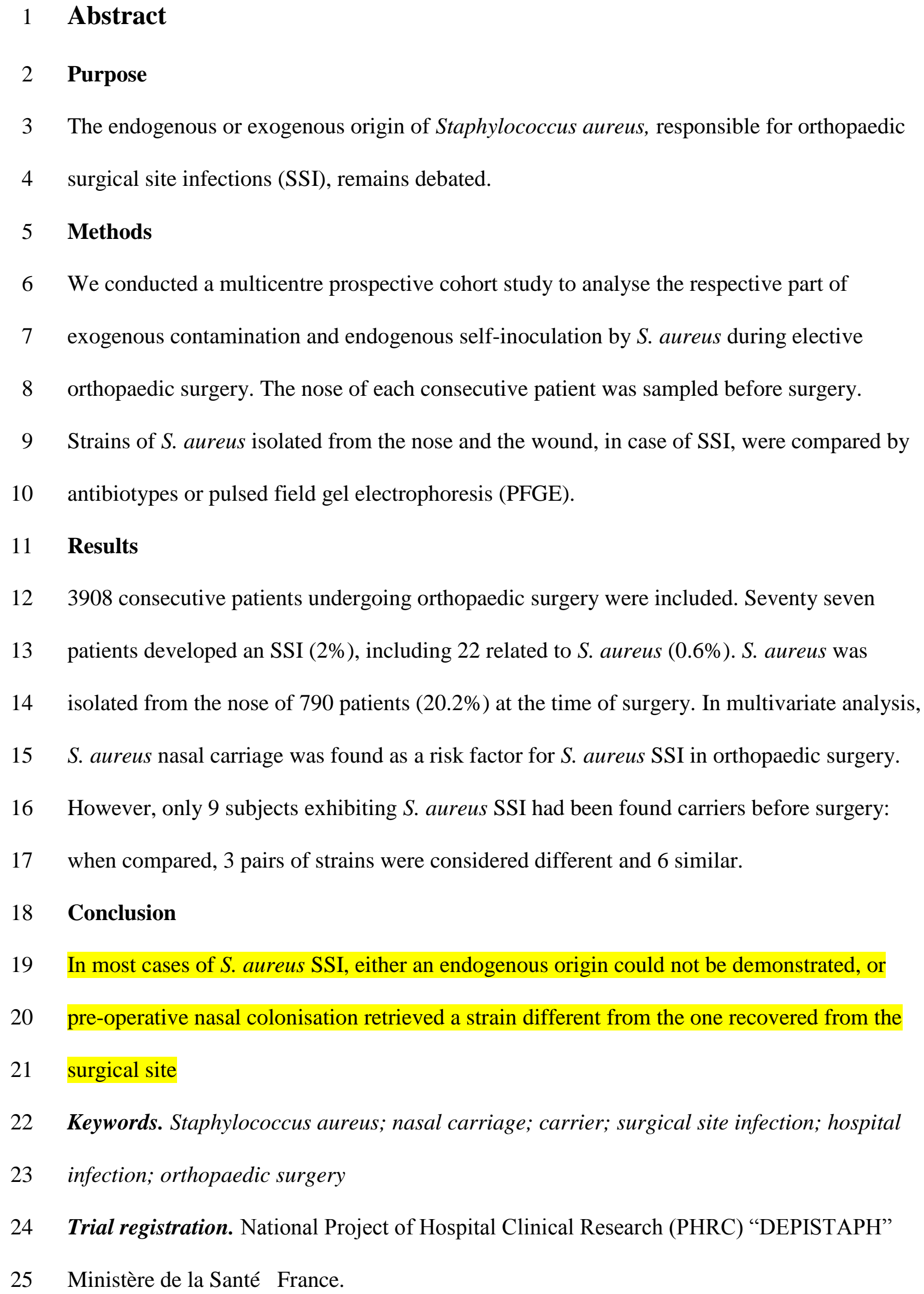




\section{Introduction}

3 The risk of prosthetic joint infection is less than 2 percent after joint replacement [1-3] or after

4 implantation of internal fracture-fixation devices [4]. However, the large number of such

5 procedures performed annually makes these infections highly significant in terms of

6 mortality, morbidity and costs, as far as the elderly population is increasing in industrialized

7 countries [5-7]. It is a well-known fact that $S$. aureus carriage predisposes to post-operative

8 staphylococcal infection in general surgery [8], in heart surgery [9-10], as in orthopaedic

9 surgery [11]. However, Kalmeijer et al. [11], in orthopaedic surgery, realized their study in

10 only one centre, with a limited number of patients. Moreover, the studies showing a

11 substantial reduction of SSI among patients receiving mupirocin were all compared to

12 historical control [8, 12-14], whilst Kalmeijer et al.[15], in a double-blind, randomised,

13 placebo-controlled study, in orthopaedic surgery, failed to show any beneficial effect. So, the exogenous pathway of contamination in orthopaedic surgery remains an important hypothesis and we undertook a large prospective multicenter cohort study, to determine whether the nasal carriage of $S$. aureus is the main pathway responsible for infection in orthopaedic SSI.

\section{Patients and methods}

We conducted a prospective epidemiological multicentre observational study to estimate the relative part of subjects with $S$. aureus nasal carriage in patients with SSI following prosthetic and internal fracture-fixation device surgery, and in non-infected patients. We compared, in SSI patients, the strains of $S$. aureus colonizing the anterior nares and that isolated from the site of infection. 
$1 \quad$ Patients. All consecutive patients undergoing scheduled orthopaedic surgery with

2 implantation of prosthesis or internal fracture-fixation device, in seventeen centres (see

3 appendix), were included from June 2003 to January 2007. A control visit was performed by

4 the surgeon at least one month and one year after surgery. Exclusion criteria were non-

5 programmed surgery and suspicion of infection at the site of surgery.

6 A written informed consent was obtained for all patients. The study protocol was approved by

7 the regional ethical research committee (Comité de Protection des Personnes Rhône-Alpes I).

8 The preparation of patients' skin included at least one preoperative shower with a soap

9 containing either chlorhexidine or polyvidone iodine, cleansing of the skin with an antiseptic

10 soap followed by a disinfection with an alcoholic antiseptic in the operative theatre. Antibiotic 11 prophylaxis was done with cefazolin, 2 grams at the anaesthetic induction. Mupirocin nasal

12 decontamination was not used whatever the results of the sampling.

13 One to three months before surgery, the study was explained to the patient during surgical

14 consultation. Written information was delivered. The nose of the patient was sampled at the

15 admission. To ensure performance and reproducibility of the nasal sampling, nurses were

16 trained and a written protocol was available in each participating unit. The patient's

17 practitioner was informed of the study and asked to refer the patient to the surgeon if a SSI

18 was suspected. In the latter case, at least 3 bacteriological samples were taken at the site of the

19 suspected infection either per-operatively (without antimicrobial prophylaxis) or by aseptic

20 aspiration using ultrasound guidance. Direct examination and bacteriological culture were

21 systematically performed.

\section{Bacteriological methods}

24 Nasal cultures: One swab was used to sample both nares and plated onto sheep blood agar

25 plate or onto specific $S$. aureus Chromastaph medium (Biomérieux, Marcy l'Etoile, France) 
1 within 24 hours after sampling if a moistened transport medium was used (Transtube®,

2 Medical Wire and Equipment Co., Corsham, England or Amies agar gel, Copan, Brescia,

3 Italy) or within 2 hours in the opposite case. Plates were incubated up to $48 \mathrm{~h}$ at $36^{\circ} \mathrm{C}$. The

4 identification of $S$. aureus isolates and their sensitivity to antibiotics were determined by

5 standard microbiological procedures.

6 As for nasal samples, swabs were cultured within 2 hours after sampling if no transport

7 medium was used, and within 24 hours in the opposite case. Fluid samples were examined by

8 light microscopy after Gram staining. They were cultured both aerobically and anaerobically

9 into blood culture bottles and monitored in an automated system. Solid samples were

10 dissected into tiny pieces with a lancet in a safety cabinet and then ground down. The

11 homogenate was cultured onto aerobic and anaerobic media. The media were incubated at

$1236^{\circ} \mathrm{C}$ for at least 48 hours for plate cultures and 15 days for liquid broths.

13 In addition to phenotypic characteristics, all the available couples of strains of S. aureus

14 isolated from the nose and the infected surgical site were compared by PFGE using SmaI. The 15 available strains were centralised in a single laboratory where PFGE was performed. Plugs 16 containing DNA were prepared following a rapid lysis procedure [16]. Bacterial cells from an 17 overnight broth culture were mixed with $1.6 \%$ of SeaPlaque agarose (Cambrex, Rockland, 18 USA). The plugs were incubated in lysis buffer containing 250 IU of lysostaphin (AMBI Inc, 19 Lawrence, NY, USA) for 2 hours at $37^{\circ} \mathrm{C}$, followed by a one-hour incubation at $50^{\circ} \mathrm{C}$ with 20 ESP buffer containing $100 \mathrm{mg} / \mathrm{L}$ of proteinase K. Plugs were rinsed with TE buffer, incubated 21 in TE with PMFS for 30 min at $37^{\circ} \mathrm{C}$ before final washing in TE buffer. The genomic DNA 22 inserts were digested at $25^{\circ} \mathrm{C}$ for $2 \mathrm{~h}$ with $20 \mathrm{UI}$ of $S m a \mathrm{I}$ enzyme. The fragments were 23 separated by PFGE with a CHEF-DrII apparatus (Biorad, Ivry sur Seine, France) in a 1.1\% 24 agarose gel (Gigaphor, Promega, Les Ullis, France) in TBE buffer, at $14^{\circ} \mathrm{C}$ under a field 25 strength of $6 \mathrm{~V} / \mathrm{cm}$ and a linear ramp of $1 \mathrm{~s}-28 \mathrm{~s}$ for 21 hours. 


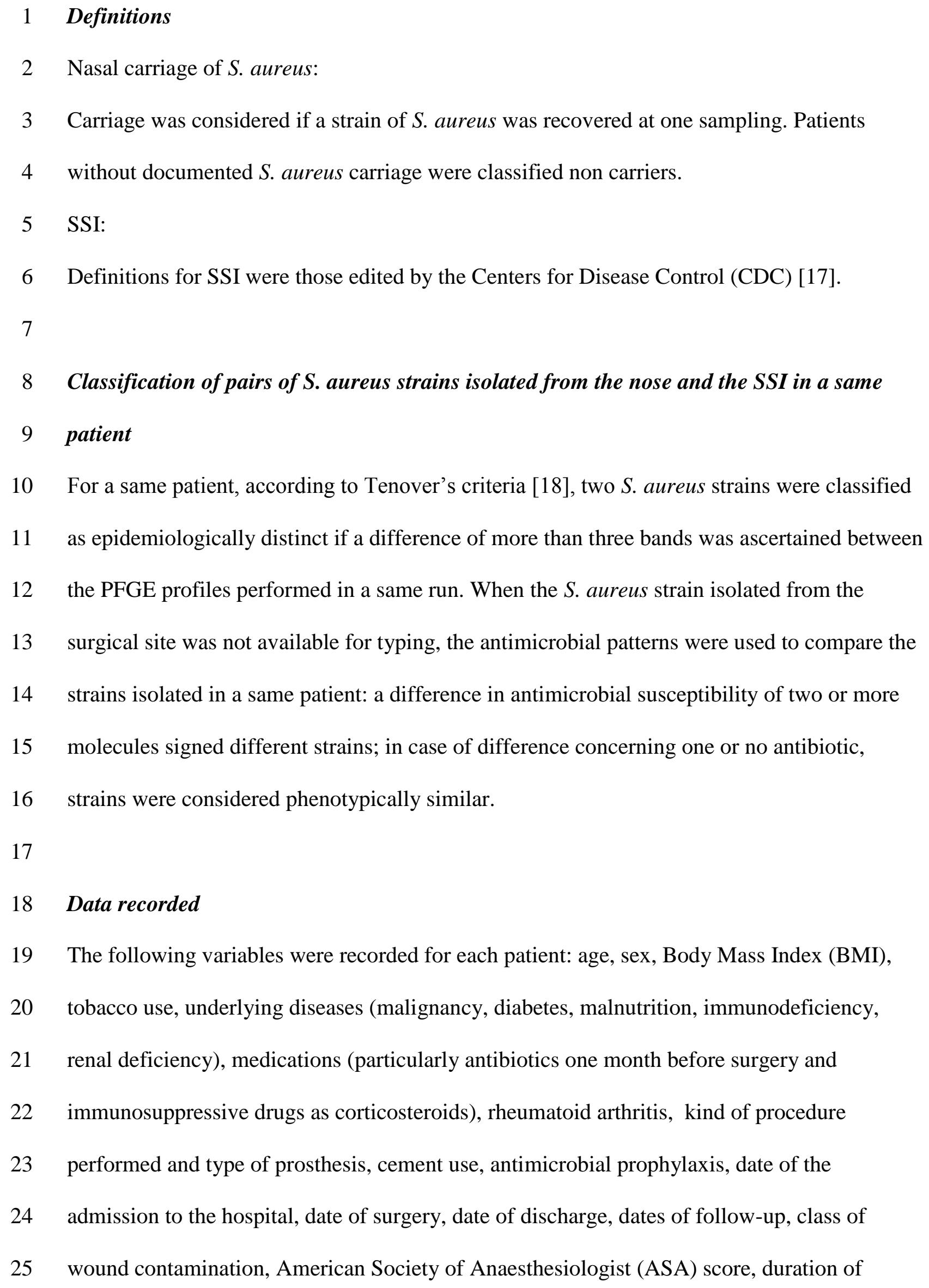




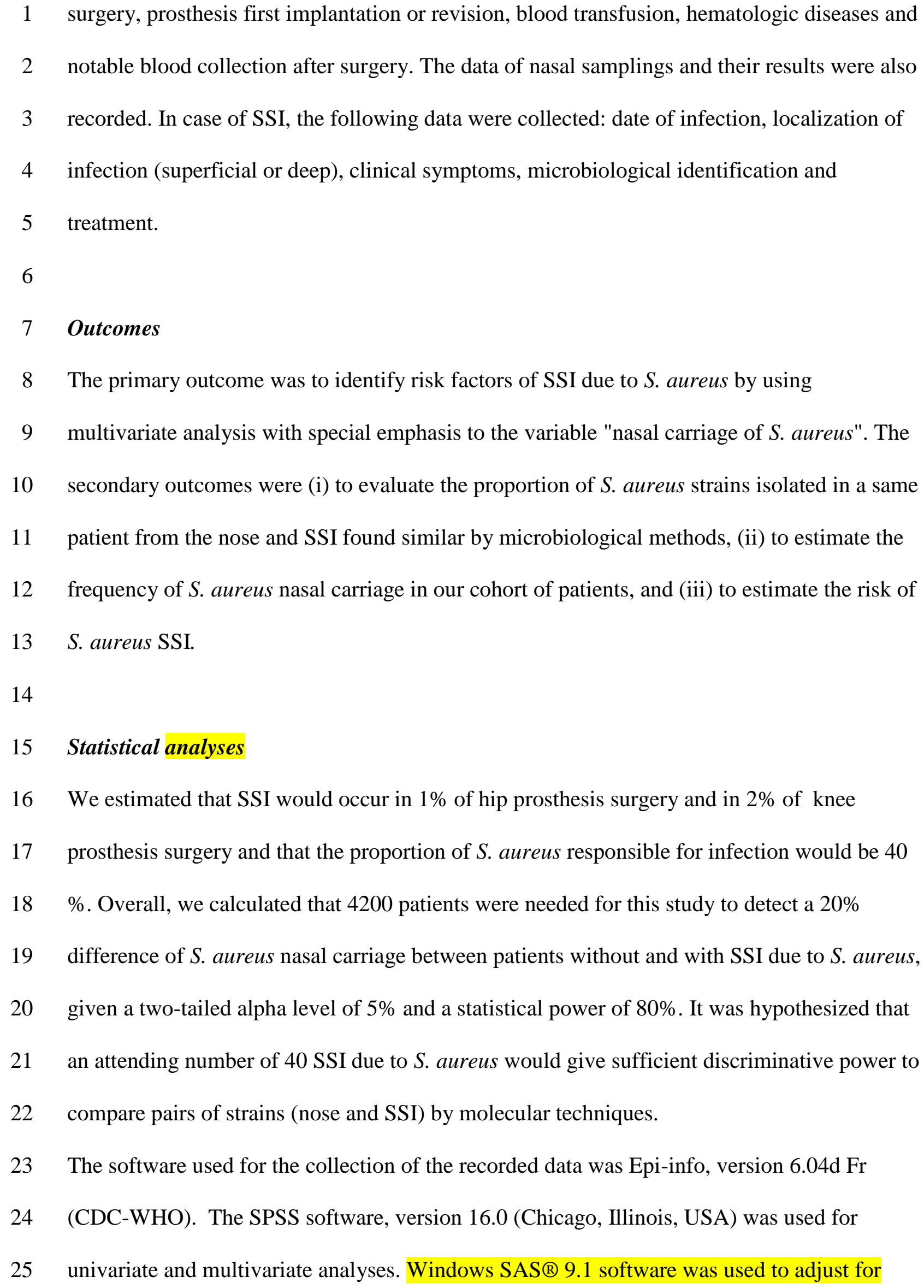

1 surgery, prosthesis first implantation or revision, blood transfusion, hematologic diseases and

2 notable blood collection after surgery. The data of nasal samplings and their results were also 3 recorded. In case of SSI, the following data were collected: date of infection, localization of

4 infection (superficial or deep), clinical symptoms, microbiological identification and

5 treatment.

Outcomes

8 The primary outcome was to identify risk factors of SSI due to S. aureus by using

9 multivariate analysis with special emphasis to the variable "nasal carriage of S. aureus". The

10 secondary outcomes were (i) to evaluate the proportion of $S$. aureus strains isolated in a same 11 patient from the nose and SSI found similar by microbiological methods, (ii) to estimate the 12 frequency of $S$. aureus nasal carriage in our cohort of patients, and (iii) to estimate the risk of 13 S. aureus SSI.

$15 \quad$ Statistical analyses

16 We estimated that SSI would occur in $1 \%$ of hip prosthesis surgery and in $2 \%$ of knee

17 prosthesis surgery and that the proportion of $S$. aureus responsible for infection would be 40

$18 \%$. Overall, we calculated that 4200 patients were needed for this study to detect a $20 \%$

19 difference of S. aureus nasal carriage between patients without and with SSI due to S. aureus, 20 given a two-tailed alpha level of $5 \%$ and a statistical power of $80 \%$. It was hypothesized that 21 an attending number of 40 SSI due to $S$. aureus would give sufficient discriminative power to 22 compare pairs of strains (nose and SSI) by molecular techniques.

23 The software used for the collection of the recorded data was Epi-info, version 6.04d Fr 24 (CDC-WHO). The SPSS software, version 16.0 (Chicago, Illinois, USA) was used for 25 univariate and multivariate analyses. Windows SAS® 9.1 software was used to adjust for 
1 cluster effect in the multivariate analysis. The rates of SSI and SSI due to S. aureus were

2 calculated globally and according to patients' nasal carriage of S. aureus and to the type of

3 device implemented. These rates were also stratified according to the NNIS index.

4 Fisher's exact test was used for analysis of categorical variables. The Wilcoxon non

5 parametric test was used for mean comparisons. Two multivariate analyses were carried out to

6 evaluate (i) risk factors for SSI and (ii) risk factors for SSI due to S. aureus. To adjust for

7 confounding factors, variables with a $P$ value below the 0.05 significance level in univariate

8 analysis were entered into a multiple logistic regression model. Because of the low number of

9 SSI infections, the multivariate analysis was run with a maximum of 3 covariates selected among the most significant in the univariate analyses. $P$ values below the $5 \%$ level were

11 considered statistically significant.

12

\section{Results}

\section{Demographic and clinical data}

The total duration of the study was 4 years ( 3 years of inclusion and one year of supplementary follow-up; end at January 2008). Four thousand and forty-six patients were included and 3908 (96.6\%) patients were evaluated. Demographic characteristics of the patients are shown in Table I. The causes for exclusion (138 patients) are described in Figure 1. Seventy-seven patients (2\%) were considered as victims of SSI. The overall infection rate was $2.2 \%$ for total hip replacement, $1.7 \%$ for knee replacement and $1.6 \%$ for partial prosthesis and fracture-fixation devices. 


\section{$1 \quad$ Microbiological data}

2 The most common infecting micro-organisms were coagulase-negative Staphylococcus spp.

3 [0.9\% of patients], followed by Staphylococcus aureus [0.6\%], and Gram negative bacteria

$4 \quad[0.4 \%]$. Of these infections, $61 \%$ arose in the first three months following surgery. There was

5 no significant change in the infection rate or type of infecting micro-organism over the course

6 of the study. As shown in Table II, 94 micro-organisms were found responsible for SSI.

7 Fourteen SSI were polymicrobial.

8 Twenty-two SSI due to S. aureus were documented; 13 of these patients were classified as

9 nasal non carriers and 9 as nasal carrier.

10 Within the strains isolated from the 13 patients classified as nasal non carriers, 8 were 11 available for typing by PFGE. All of these strains exhibited independent profiles (data not

12 shown). The 5 remaining strains were isolated from patients hospitalized in 5 different

13 centres, excluding cross transmission.

14 In patients classified as nasal carriers, the 9 couples of strains isolated from SSI and nasal 15 specimen were compared according to their genotype (4 cases) and/or their antimicrobial 16 susceptibility ( 5 cases). From the 4 pairs of strains compared by PFGE, 2 pairs exhibited

17 different profiles whereas 2 other pairs were shown to share a similar profile according to

18 Tenover's criteria (Figure 2). All of these strains were different from those isolated from

19 infected patients classified as non carriers (data not shown). For the 5 remaining cases, nasal 20 samples were not available for typing in 2 cases and, in 3 cases, strains recovered from the 21 surgical site were not stored because isolated in laboratories located outside an university 22 hospital; when compared according to antibiotypes, one of these 5 pairs was classified 23 different whereas the four others were classified similar because of identical or minor 24 differences in antimicrobial susceptibility (see footnotes of Table III for details). 
1 Overall, by combining the results of genotypic and phenotypic typing methods, from a total of

222 S. aureus SSI, no $S$. aureus nasal carriage was noted in 13 patients; in the 9 remaining

3 patients, 3 pairs of strains were different and 6 pairs were similar (Table III). So, with the

4 hypothesis of maximum bias, at least 16 of the 22 cases of $S$. aureus SSI were independent of

5 nasal carriage of $S$. aureus at the time of surgery.

6

\section{SSI and nasal carriage}

8 S. aureus was isolated in the nose of 790 patients at the time of surgery (20.2\%). Methicillin

9 resistant S. aureus (MRSA) strains were isolated in only $0.6 \%$ of patients. The overall risk of

\section{Risk factors for SSI}

Univariate and multivariate analyses were performed to assess the risk factors for SSI (Table

IV). In multivariate analysis, significant risk factors were tobacco use, wound haematoma and

NNIS score for the occurrence of SSI., nasal carriage together with tobacco use and NNIS

score for SSI due to S. aureus (Table IV).

\section{Discussion}

The present study is, to our knowledge, the largest evaluation of nasal carriage of S. aureus in patients undergoing orthopaedic surgery. It confirms that nasal carriage of S. aureus at the time of surgery is a risk factor for S. aureus SSI in orthopaedic surgery. However 13 out of 22 S. aureus SSI occurred in non carriers, and the majority (16/22) of S. aureus SSI were 
1 independent of nasal carriage, suggesting an exogenous pathway of contamination. Recently,

2 two studies performed in cardiothoracic surgery [19] and in general surgery [20] showed that

3 endogenous nasal contamination was the major acquisition pathway for methicillin-

4 susceptible $S$. aureus (MSSA), whereas exogenous acquisition pathway was essential for

5 methicillin-resistant S. aureus (MRSA), underscoring the crucial role of hospital infection

6 control measures.

7 Several criticisms can be addressed to our study. First, we have limited the sampling to the

8 anterior nares since this site is considered to be the primary colonization site of S. aureus [21,

922 ]. Recently [23], a large study has highlighted the importance of the throat as a significant

10 site of S. aureus carriage, with an additional sensitivity of $25.7 \%$ when combined to nasal

11 sampling. It confirmed, however, that the anterior nares are the most colonized site with $S$.

12 aureus. Our protocol included initially a rectal swabbing before surgery; however, since many

13 patients denied this sample, the data regarding rectal specimens could not be taken into

14 consideration. With a single nasal sample and in the absence of additional throat and rectal

15 specimens, the frequency of carriage of $S$. aureus in our cohort was certainly underestimated, 16 as illustrated by the figure of $20.2 \%$ of nasal carriers in this study compared to $37.1 \%$ in the 17 one of Mertz et al [23] that combined nasal and throat samplings. Second, we obtained only 18 one qualitative (and not quantitative) nasal sample from each patient. However, the most 19 predictive factor for S. aureus infections is the persistent carriage pattern [24]. Getting up to 20 seven nasal swab cultures to accurately segregate non-carriers from intermittent carriers, as 21 suggested by Nouwen et al. [25], was not practically feasible for such a large effective. 22 Indeed, most $S$. aureus screening programs require only one swabbing of the anterior nares [8, $2313,15]$. Third, with an end-point at 1 year after the device implantation, we missed late 24 infections (> 2 years) [26]. However, the latter infections are not systematically attributed to a 25 per-operative contamination and are mostly caused by organisms other than S. aureus [4]. 
1 Fourth, and this is the major weakness of our study, many strains of S. aureus were not

2 available for molecular typing because infection was often detected outside the surgical

3 setting and the corresponding laboratory omitted to keep the strain.

4 Despite these criticisms, in our study, with the hypothesis of maximum bias, at least 16 of the

522 cases of S. aureus SSI were not related to $S$. aureus nasal carriage before surgery. The

6 origin of S. aureus may be another site of carriage, such as throat [23], perineum or digestive

7 tract $[27,28]$. Indeed, throat or intestinal carriage without nasal carriage occurs relatively

8 frequently [23, 27], which can provide a rationale to investigate this reservoir for

9 endogenous origin of S. aureus infection. Orthopaedic SSI can also result from exogenous

10 transmission, as it has been already shown, notably from the hospital environment and from

11 health-care workers [29, 30]. It is noteworthy that, in our study, no cross transmission of $S$.

12 aureus within centres was documented. Our results could explain why in general surgery [9]

13 and in orthopaedic surgery [15], randomised controlled trials with mupirocin, eliminating

14 solely the nasal carriage, were unable to reduce $S$. aureus SSI. Concerning the strategies to

15 prevent SSI, in the more recent SHEA/IDSA practice recommendations, the routine screening

16 for S. aureus carriage or attempts to decolonize surgical patients with an antistaphylococcal

17 agent in the preoperative setting remains unsolved issues [31].

18 In conclusion, nasal carriage of S. aureus at the time of surgery, as investigated in this study,

19 is a risk factor for S. aureus SSI in orthopaedic surgery. However, screening for S. aureus of

20 the nares only, did not reliably predict S. aureus SSI. In most cases of S. aureus SSI, either an 21 endogenous origin could not be demonstrated, or pre-operative nasal colonisation retrieved a 22 strain different from the infecting pathogen. Further studies are necessary to elucidate the role 23 of extra-nasal S. aureus carriage and the potential role of exogenous sources of contamination 24 in elective orthopaedic surgery. As pointed out by our results, non S. aureus nasal carriers 
must also be taken into account arguing for the importance of implementing robust standard prevention strategies for SSI.

\section{STUDY GROUP MEMBERS}

Seventeen French Centres have contributed to this clinical trial. The authors thank : the University Hospital of Saint-Etienne (MH.Fessy1, F.Farizon", AC.Vautrin'); the "Clinique Mutualiste" of Saint-Etienne (JP.Passot ${ }^{1}$, JP.Fayard ${ }^{1}$, F.Chalencon ${ }^{1}$, JM.Semay ${ }^{1}$, L.Dupre La Tour ${ }^{1}$, L.Beguin ${ }^{1}$, R.Meley ${ }^{2}$ ); the "Centre Hospitalier Privé de la Loire of Saint-Etienne" (A.Mesguich", DG.Avet ${ }^{1}$, PH.Charlier ${ }^{1}$, M.Rousson ${ }^{2}$ ); the "Clinique du Parc" of SaintEtienne (L.Charmion ${ }^{1}$, E.Puech ${ }^{2}$ ); the Military Hospital Desgenettes of Lyon (JP.Romanet ${ }^{1}$, F.Rongiéras ${ }^{1}$, P.Lainé $^{1}$, F.Chauvin ${ }^{1}$, M.Branfaux ${ }^{1}$, B.Chevalier ${ }^{2}$ ); the University Hospital of Lyon (J.Bejuin-Hugues ${ }^{1}$, JP.Carret ${ }^{1}$, P.Neyret $^{1}$, F.Lecuire ${ }^{1}$, J.Rubini ${ }^{1}$, M.Basso ${ }^{1}$, I.Benareau ${ }^{1}$, P.Girardo ${ }^{2}$, S.Tigaud ${ }^{2}$, J.Carrere ${ }^{2}$, C.Galabert ${ }^{2}$, D. Peyramond ${ }^{3}$ ); the "Clinique Sainte-Anne" of Lyon (M.Bonnin ${ }^{1}$, JP.Hager ${ }^{1}$, P.Chambat ${ }^{1}$, A.François ${ }^{2}$ ); the University Hospital of Grenoble (JP.Stahl ${ }^{1}$, P.Merloz ${ }^{1}$, J.Croize ${ }^{2}$, JP Stahl ${ }^{3}$ ); the "Clinique des Cévennes" of Annonay (A.Mironneau ${ }^{1}$, E.Forestier ${ }^{2}$ ); the Hospital of Montbrison (P.Girardin ${ }^{1}$, Dr F.Crepet ${ }^{2}$ ); the Hospital of Roanne (A.Durand ${ }^{1}$, W.Tohoubi ${ }^{1}$, Dr D.Raou ${ }^{1}$, Dr M.Boyer ${ }^{2}$ ); the "Clinique Orthopédique Médico-Chirurgicale" of Dracy-le-Fort (Dr P.Deroche ${ }^{1}$, G.Deschamps ${ }^{1}$, S.Rizk ${ }^{1}$, C.Chol ${ }^{1}$, P.Ragois ${ }^{1}$, C.Pomel ${ }^{2}$ ); the University Hospital of Nimes (G.Asencio", R.Bertin', N.Bouziges", A.Sotto ${ }^{3}$ ); the "Clinique Clairval" of Marseille (D.Prost ${ }^{1}$, JF.Thiery ${ }^{1}$, M.Chickly ${ }^{1}$, A.Merabet-Sigwalt ${ }^{2}$ ) and the University Hospital of Nice (P.Boileau ${ }^{1}$, G.Armando ${ }^{1}$, H.Carsenti ${ }^{2}$, P.Dellamonica ${ }^{3}$ ).

\section{Acknowledgments}

The authors thank particularly Nicolas Eydoux, Estelle Badel and Fabrice Di Palma for the collection and recording of data.

${ }^{1}=$ Orthopedic Surgeon; ${ }^{2}=$ Microbiologist ${ }^{3}=$ Infectious Diseases Consultant

\section{Contributors}


PB, CC and FL participated in the design of the study, in the collection, analysis, and interpretation of the clinical data, in the writing of the report and the decision to submit the paper for publication. FG and BP participated in the 4 collection, analysis and interpretation of the microbiological data. JPP, JPF, JB, MHF, FF participated in various 5 aspects of trial conduct and patient referral. All authors had full access to all of the data in this study and take 6 complete responsibility for the integrity of the data and the accuracy of the data analysis. 


\section{References}

1. Harris WH, Sledge CB. Total hip and total knee replacement (1990) N Engl J Med 323:801-7.

2. Sperling JW, Kozak TK, Hanssen AD, Cofield RH (2001) Infection after shoulder arthroplasty. Clin Orthop 382:206-16.

3. Chesney D, Sales J, Elton R, Brenkel IJ (2008) Infection after knee arthroplasty: a prospective study of 1509 cases. J Arthroplasty 23:355-9.

4. Trampuz A, Zimmerli W (2006) Diagnosis and treatment of infections associated with fracture-fixation devices. Injury S37:S59-S66.

5. Powers KA, Terpenning MS, Voice RA, Kauffman C (1990) Prosthetic joint infections in the elderly. Am J Med 88:9N-13N.

6. NIH Consensus Development Panel on Total Hip Replacement (1995) NIH consensus conference: total hip replacement. JAMA 273:1950-6.

7. Darouiche RO (2004) Treatment of infections associated with surgical implants. N Engl J Med 350:1422-9.

8. Kalmeijer MD, van Nieuwland-Bollen E, Bogaers-Hofman D, de Baere GA (2000) Nasal carriage of Staphylococcus aureus is a major risk factor for surgical-site infections in orthopaedic surgery. Infect Control Hosp Epidemiol 21:319-23.

9. Perl TM, Cullen JJ, Wenzel RP, Zimmerman MB, Pfaller MA, Sheppard D, et al (2002) Intranasal mupirocin to prevent postoperative Staphylococcus aureus infections. N Engl J Med 346: 1871-7.

10. Kluytmans JA, Mouton JW, Ijzerman EP, Vandenbroucke-Grauls CM, Maat AW, Wagenvoort JH, Verbrugh HA (1995) Nasal carriage of Staphylococcus aureus as a major risk factor for wound infections after cardiac surgery. J Infect Dis 171:216-9.

11. Muñoz P, Hortal J, Giannella M, Barrio JM, Rodríguez-Créixems M, Pérez MJ, Rincón C, Bouza E (2008) Nasal carriage of Staphylococcus. aureus increases the risk of surgical site infection after major heart surgery. J Hosp Infect 68:25-31.

12. Gernaat-van der Sluis AJ, Hoogenboom-Verdegaal AM, Edixhoven PJ, Spies-van Rooijen (1998) Prophylactic mupirocin could reduce orthopedic wound infections. 1,044 patients treated with mupirocin compared with 1,260 historical controls. Acta Orthop Scand 69:412-4.

13. Rao N, Cannella B, Crossett LS, Yates AJ Jr, McGough R 3rd (2008) A preoperative decolonization protocol for Staphylococcus aureus prevents orthopedic infections. Clin Orthop Relat Res. 66:1343-8.

14. Hacek DM, Robb WJ, Paule SM, Kudrna JC, Stamos VP, Peterson LR (2008) Staphylococcus aureus nasal decolonization in joint replacement surgery reduces infection. Clin Orhtop Relat Res 466:1349-55.

15. Kalmeijer MD, Coertjens H, van Nieuwland-Bollen PM, Bogaers-Hofman D, de Baere GA, Stuurman A, van Belkum A, Kluytmans JA (2002) Surgical site infections in orthopaedic surgery: the effect of mupirocin nasal ointment in a double-blind, randomized, placebo-controlled study. Clin Infect Dis 35:353-8. 
16. Matushek MG, Bonten MJ, Hayden MK (1996) Rapid preparation of bacterial DNA for pulsed-field gel electrophoresis. J Clin Microbiol. 34:2598-600.

17. Horan TC, Gaynes RP, Martone WJ, Jarvis WR, Emori TG (1992) CDC definitions of nosocomial surgical site infections, 1992: a modification of CDC definitions of surgical wound infections. Am J Infect Control 20:271-4.

18. Tenover FC, Arbeit RD, Goering PA, Mickelsen PA, Murray BE, Persing DH, Swaminathan B (1995) Interpretating chromosomal DNA restriction patterns produced by pulsed-field gel electrophoresis : criteria for bacterial strain typing. J Clin Microbiol 33:2233-9.

19. San Juan R, Chaves F, Lopez Gude J, Díaz-Pedroche C, Otero J, Cortina Romero JM, Rufilanchas JJ, Aguado JM (2007) Staphylococcus aureus poststernotomy mediastinitis: description of two distinct acquisition pathways with different potential preventive approaches. J Thorac Cardiovasc Surg 104:6706.

20. Harbarth S, Huttner B, Gervaz P, Fankhauser C, Chraiti MN, Schrenzel J, Licker M, Pittet D (2008) Risk factors for methicillin-resistant Staphylococcus aureus surgical site infection. Infect Control Hosp Epidemiol 29: 890-3.

21. Kluytmans J, van Belkum A, Verbrugh H. Nasal carriage of Staphylococcus aureus: epidemiology, underlying mechanisms, and associated risks (1997) Clin Microbiol Rev 10:505-20.

22. Lowy FD (1998) Staphylococcus aureus infections. N Engl J Med 339:520-32.

23. Mertz D, Frei R, Jaussi B, Tietz A, Stebler C, Flückiger U, Widmer AF (2007) Throat swabs are necessary to reliably detect carriers of Staphylococcus aureus. Clin Infect Dis 45:475-7

24. Van Belkum A, Verkaik NJ, de Vogel CP, Boelens HA, Verveer J, Nouwen JL, Verbrugh HA, Wertheim HF (2009) Reclassification of Staphylococcus aureus nasal carriage types. J Infect Dis. 199:1820-6

25. Nouwen JL, Ott A, Kluytmans-Vandenbergh MF, Boelens HA, Hofman A, van Belkum A, Verbrugh HA (2004) Predicting the Staphylococcus aureus nasal carrier state: derivation and validation of a "culture rule". Clin Infect Dis 39:806-11.

26. Schafroth M, Zimmerli W, Brunazzi M, Ochsner PE (2003) Infections. In: Oschner PE, ed. Total hip replacement. Berlin: Springer-Verlag,:65-90

27. Acton DS, Plat-Sinnige MJ, van Wamel W, de Groot N, van Belkum A (2009) Intestinal carriage of Staphylococcus aureus: how does its frequency compare with that of nasal carriage and what is its clinical impact? Eur J Clin Microbiol Infect Dis 28: 115-27.

28. Wertheim HFL, Melles DC, Vos MC, van Leeuwen W, van Belkum A, Verbrugh HA, Nouwen JL (2005) The role of nasal carriage in Staphylococcus aureus infections. Lancet Inf Dis 5:751-62.

29. Murdoch DR, Roberts SA, Fowler VG Jr, Shah MA, Taylor SL, Morris AJ, Corey GR (2001) Infection of orthopaedic prostheses after Staphylococcus aureus bacteremia. Clin Infect Dis 32:646-9.

30. Blok HE, Troelstra A, Kamp-Hopmans TE, Gigengack-Baars AC, Vandenbroucke-Grauls CM, Weersink AJ, Verhoef J, Mascini EM (2003) Role of healthcare workers in outbreaks of methicillinresistant Staphylococcus aureus: a 10-year evaluation from a Dutch university hospital. Infect Control Hosp Epidemiol 24:679-85. 
1 31. Anderson DJ, Kaye KS, Classen D, Arias KM, Podgorny K, Burstin H, et al (2008). Strategies to

1

2

3

4

5

6

7

8

9

10

11

12

13

14

15

16

17

18

19

20

21

22

23

24

25

26

27

28

29

30

31

32

33

34

35

36

37

38

39

40

41

42

43

44

45

46

47

48

49

50

51

52

53

54

55

56

57

58

59

60

61

62

63

64

65 prevent surgical site infections in acute care hospital. Infect Control Hosp Epidemiol 29: S51-S61. 
1

2

3

4
2

3 Figure 1: Frequency of surgical site infection according to the type of prosthesis implemented 4

5 Figure 2: SmaI PFGE profiles of strains of $S$. aureus isolated from four patients for whom the

6 nasal isolate(s) and the surgical site isolate(s) were available. Strain of S. aureus NTCC 8322

7 was used as a size marker. * indicates the reference size marker, $\mathrm{N}$ : nasal strain, $\mathrm{I}:$ isolate

8 from SSI, $\mathrm{S}$ : isolate from stools 
Table I: Main characteristics of the 3908 patients included in the study according to the type of osteosynthetic surgery

3

4

\begin{tabular}{|c|c|c|c|c|c|}
\hline Type of osteosynthetic surgery & Hip prosthesis & $\begin{array}{c}\text { Knee } \\
\text { prosthesis }\end{array}$ & $\begin{array}{c}\text { Uni } \\
\text { compartmental } \\
\text { knee prosthesis }\end{array}$ & Others & Total \\
\hline Number of patients (\%) & $2321(59.4 \%)$ & $1162(29.7 \%)$ & $292(7.5 \%)$ & $133(3.4 \%)$ & $3908(100 \%)$ \\
\hline Mean age $(+/-\mathrm{SD})$ & $67.7(+/-10.8)$ & $72.9(+/-7.9)$ & $72.7(+/-7.2)$ & $76.6(+/-10.3)$ & $69.9(+/-10.0)$ \\
\hline Male (\%) & $1121(48.3 \%)$ & $408(35.1 \%)$ & $91(31.2 \%)$ & $58(43.0 \%)$ & $1678(43.0 \%)$ \\
\hline Diabetes $(\%)$ & $211(9.0 \%)$ & $159(13.7 \%)$ & $37(12.7 \%)$ & $13(9.6 \%)$ & $420(10.7 \%)$ \\
\hline Immunocompromised patients ${ }^{\mathrm{a}}$ & $5(0.2 \%)$ & $5(0.4 \%)$ & $1(0.3 \%)$ & $0(0 \%)$ & $11(0.3 \%)$ \\
\hline Cigarette use & $445(19.2 \%)$ & $152(12.9 \%)$ & $28(9.6 \%)$ & $17(12.6 \%)$ & $642(16.4 \%)$ \\
\hline Rheumatoid polyarthritis & $50(2.1 \%)$ & $31(2.7 \%)$ & $2(0.7 \%)$ & $7(5.2 \%)$ & $90(2.3 \%)$ \\
\hline Antibiotic use one month prior & $97(4.2 \%)$ & $49(4.2 \%)$ & $10(3.4 \%)$ & $8(5.9 \%)$ & $164(4.2 \%)$ \\
\hline Corticosteroids use & $75(3.2 \%)$ & $35(3.0 \%)$ & $6(2.1 \%)$ & $6(4.4 \%)$ & $122(3.1 \%)$ \\
\hline Cancer & $227(9.8 \%)$ & $130(11.2 \%)$ & $35(12.0 \%)$ & $16(11.9 \%)$ & $408(10.4 \%)$ \\
\hline Renal disease & $8(0.3 \%)$ & $2(0.2 \%)$ & $0(0 \%)$ & $0(0 \%)$ & $10(0.3 \%)$ \\
\hline Bacteriuria & $50(2.2 \%)$ & $23(2.0 \%)$ & $4(1.4 \%)$ & $3(2.2 \%)$ & $80(2.1 \%)$ \\
\hline Blood transfusion & $182(7.8 \%)$ & $156(13.4 \%)$ & $1(0.3 \%)$ & $24(17.8 \%)$ & $363(9.3 \%)$ \\
\hline Notable hematoma & $28(1.2 \%)$ & $16(1.4 \%)$ & $4(1.4 \%)$ & $0(0 \%)$ & $48(1.2 \%)$ \\
\hline \multicolumn{6}{|l|}{ Cement use for prosthesis } \\
\hline 1- cement & $58(2.5 \%)$ & $418(36.0 \%)$ & $25(8.6 \%)$ & $47(33.8 \%)$ & $548(14.0 \%)$ \\
\hline 2 - partially cemented & $248(10.7 \%)$ & $359(30.9 \%)$ & $7(2.4 \%)$ & $9(6.8 \%)$ & $623(16.0 \%)$ \\
\hline 3 - no cement & $2017(86.8 \%)$ & $384(33.0 \%)$ & $260(89.0 \%)$ & $76(57.1 \%)$ & $2737(70.0 \%)$ \\
\hline Primo implementation & $2254(97.1 \%)$ & $1134(97.6 \%)$ & $288(98.6 \%)$ & $13(9.6 \%)$ & $3689(94.4 \%)$ \\
\hline SSI frequency & $2.2 \%$ & $1.7 \%$ & $0.7 \%$ & $3.8 \%$ & $2.0 \%$ \\
\hline \multicolumn{6}{|l|}{$\begin{array}{l}\text { SSI frequency according to } \\
\text { NNIS index }\end{array}$} \\
\hline 0 & $1.5 \%$ & $0.9 \%$ & $1.0 \%$ & $2.2 \%$ & $1.3 \%$ \\
\hline 1 & $3.8 \%$ & $3.3 \%$ & $0 \%$ & $5.3 \%$ & $3.3 \%$ \\
\hline 2 & $4.9 \%$ & $5.6 \%$ & $0 \%$ & $20.0 \%$ & $6.6 \%$ \\
\hline Frequency of SSI due to $S$. & $0.8 \%$ & $0.2 \%$ & $0 \%$ & $2.3 \%$ & $0.6 \%$ \\
\hline \multicolumn{6}{|l|}{$\begin{array}{l}\text { Frequency of SSI due to } S \text {. } \\
\text { aureus according to NNIS }\end{array}$} \\
\hline index $\quad 0$ & $0.3 \%$ & $0.1 \%$ & $0 \%$ & $2.3 \%$ & $0.3 \%$ \\
\hline 1 & $2.0 \%$ & $0.3 \%$ & $0 \%$ & $0 \%$ & $1.3 \%$ \\
\hline 2 & $1.6 \%$ & $0 \%$ & $0 \%$ & $20.0 \%$ & $1.9 \%$ \\
\hline
\end{tabular}

${ }^{\mathrm{a}}$ Immunocompromised patients: malignancy, transplantation, immunosuppressive therapy, HIV infection 
Table II: Microbiological data

Bacterium Number

Coagulase negative Staphylococcus spp. 36

Methicillin susceptible S. aureus

Methicillin resistant $S$. aureus

4

Enterobacteriacae

Enterococcus spp.

Streptococcus spp.

6

Propionibacterium acnes

3

Pseudomonas aeruginosa

2

Corynebacterium spp.

2

Pseudomonas paucimobilis

1

Clostridium perfringens

1

Fusobacterium spp.

1

Peptostreptococcus spp.

1

Acinetobacter spp.

1

Including polymicrobial infections

14 
Table III: Detailed results of the 22 cases of SSI due to S. aureus and their relationship with nasal carriage.

\begin{tabular}{|c|c|c|c|c|c|c|}
\hline Patient & $\begin{array}{l}\text { Type of } \\
\text { surgery }\end{array}$ & $\begin{array}{l}\text { No. of days } \\
\text { between } \\
\text { surgery } \\
\text { and SSI }\end{array}$ & $\begin{array}{l}\text { Bacterial strain } \\
\text { responsible for } \\
\text { SSI }^{\mathbf{a}}\end{array}$ & $\begin{array}{l}\text { Nasal } \\
\text { sampling } \\
\text { before } \\
\text { surgery }^{\text {a }}\end{array}$ & $\begin{array}{l}\text { Other nasal } \\
\text { samplings }^{\mathbf{a}}\end{array}$ & $\begin{array}{l}\text { Classification of } \\
\text { pairs of } S \text {. aureus } \\
\text { isolated from the } \\
\text { nose and the SSI }\end{array}$ \\
\hline 1 & $\begin{array}{l}\text { Hip } \\
\text { prosthesis }\end{array}$ & 15 & MSSA (I4) & Positive (N3) & & $\begin{array}{l}\text { different (PFGE } \\
\text { and AP) }\end{array}$ \\
\hline 2 & $\begin{array}{l}\text { Knee } \\
\text { prosthesis }\end{array}$ & 15 & MSSA & Negative & & \\
\hline 3 & $\begin{array}{l}\text { Hip } \\
\text { prosthesis }\end{array}$ & 26 & MRSA & Positive & $\begin{array}{l}\text { positive one month } \\
\text { after SSI diagnosis }\end{array}$ & similar $(\mathrm{AP})^{\mathrm{b}}$ \\
\hline 4 & $\begin{array}{l}\text { Hip } \\
\text { prosthesis }\end{array}$ & 22 & MSSA & Negative & & \\
\hline 5 & $\begin{array}{l}\text { Hip } \\
\text { prosthesis }\end{array}$ & 25 & MSSA & Positive & $\begin{array}{l}\text { positive } 2 \text { months } \\
\text { after SSI diagnosis }\end{array}$ & different $(\mathrm{AP})^{\mathrm{c}}$ \\
\hline 6 & $\begin{array}{l}\text { Hip } \\
\text { prosthesis }\end{array}$ & 25 & MSSA & Negative & $\begin{array}{l}\text { positive at the time of } \\
\text { SSI diagnosis }\end{array}$ & \\
\hline 7 & $\begin{array}{l}\text { Hip } \\
\text { prosthesis }\end{array}$ & 30 & MSSA & Negative & & \\
\hline 8 & $\begin{array}{l}\text { Hip } \\
\text { prosthesis }\end{array}$ & 20 & MRSA & Negative & & \\
\hline 9 & $\begin{array}{l}\text { Partial hip } \\
\text { prosthesis } \\
\text { replacement }\end{array}$ & 24 & MSSA & Negative & & \\
\hline 10 & $\begin{array}{l}\text { Hip } \\
\text { prosthesis }\end{array}$ & 19 & MSSA & Negative & & \\
\hline 11 & $\begin{array}{l}\text { Hip } \\
\text { prosthesis }\end{array}$ & 22 & MSSA & Positive & $\begin{array}{l}\text { positive } 2 \text { months } \\
\text { after SSI diagnosis }\end{array}$ & similar $(\mathrm{AP})^{\mathrm{d}}$ \\
\hline 12 & $\begin{array}{l}\text { Hip } \\
\text { prosthesis }\end{array}$ & 43 & MSSA (I9) & Positive (N8) & $\begin{array}{l}\text { nose sampling } \\
\text { number } 2 \text { positive }\end{array}$ & $\begin{array}{l}\text { similar (PFGE and } \\
\text { AP) }\end{array}$ \\
\hline 13 & $\begin{array}{l}\text { Hip } \\
\text { prosthesis }\end{array}$ & 35 & MSSA & Negative & & \\
\hline 14 & $\begin{array}{l}\text { Hip } \\
\text { prosthesis }\end{array}$ & 20 & MSSA & Negative & & \\
\hline 15 & $\begin{array}{l}\text { Hip } \\
\text { prosthesis }\end{array}$ & 23 & MSSA (I2) & Positive (N1) & & $\begin{array}{l}\text { similar (PFGE and } \\
\text { AP) }\end{array}$ \\
\hline 16 & $\begin{array}{l}\text { Hip } \\
\text { prosthesis }\end{array}$ & 62 & MSSA & Negative & 2 negative samplings & \\
\hline 17 & $\begin{array}{l}\text { Knee } \\
\text { prosthesis } \\
\text { replacement }\end{array}$ & 82 & MRSA & Negative & & \\
\hline 18 & $\begin{array}{l}\text { Knee } \\
\text { prosthesis }\end{array}$ & 41 & MSSA & Positive & $\begin{array}{l}\text { positive } 13 \text { days after } \\
\text { SSI diagnosis }\end{array}$ & similar $(\mathrm{AP})^{\mathrm{e}}$ \\
\hline 19 & $\begin{array}{l}\text { Hip } \\
\text { prosthesis }\end{array}$ & 42 & MSSA & Positive & $\begin{array}{l}\text { negative } 2 \text { months } \\
\text { after SSI diagnosis }\end{array}$ & similar $(\mathrm{AP})^{\mathrm{f}}$ \\
\hline 20 & $\begin{array}{l}\text { Hip } \\
\text { prosthesis }\end{array}$ & 73 & MSSA & Negative & & \\
\hline 21 & $\begin{array}{l}\text { Hip } \\
\text { prosthesis }\end{array}$ & 41 & $\begin{array}{l}\text { MSSA } \\
+ \text { Klebsiella } \\
\text { pneumoniae }\end{array}$ & Negative & & \\
\hline 22 & $\begin{array}{l}\text { Hip } \\
\text { prosthesis }\end{array}$ & 63 & $\begin{array}{l}\text { MRSA (I7) } \\
+ \text { Pseudomonas } \\
\text { aeruginosa }\end{array}$ & $\begin{array}{l}\text { Positive } \\
\text { (MSSA) } \\
\text { (N5) }\end{array}$ & $\begin{array}{c}\text { positive MRSA (S6) } \\
\text { in stools five } \\
\text { days before SSI }\end{array}$ & $\begin{array}{l}\text { Different (PFGE } \\
\text { and AP) }\end{array}$ \\
\hline
\end{tabular}

SSI = surgical site infection; AP = antimicrobial profile; MSSA = Methicillin susceptible S. aureus; MRSA = Methicillin resistant $S$. aureus $; \mathrm{PFGE}=$ Pulsed Field Gel Electrophoresis . 
${ }^{\text {a }}$ Figures in brackets correspond to the numbering of $S$. aureus isolates in Fig. 2

${ }^{\mathrm{b}}$ patient 3 harbored nasal and SSI MRSA strains that were both sensitive to all aminoglycosides but resistant to erythromycin and lincomycin.

${ }^{c}$ patient 5 harbored distinct $S$. aureus strains: the nasal strain was only resistant to penicillin $\mathrm{G}$ and intermediate to norfloxacin whereas the SSI strain was resistant to penicillin $\mathrm{G}$ and erythromycin and sensitive to norfloxacin. ${ }^{\mathrm{d}}$ patient 11 harbored nasal and SSI MSSA strains that were both sensitive to all tested antibiotics except penicillin $\mathrm{G}$.

e patient 18 harbored nasal and SSI MSSA strains both only resistant to penicillin G.

${ }^{\mathrm{f}}$ patient 19 Nasal strain was only resistant to penicillin G although the SSI strain was resistant to penicillin G and intermediate to pristinamycin 
Table IV: Univariate and multivariate analysis of risk factors for SSI overall and SSI due to S. aureus

\begin{tabular}{l|c|cc}
\hline Risks factors & Univariate analysis & \multicolumn{2}{c}{ Multivariate analysis } \\
\hline For SSI overall & $P$ & $P$ & Exp (B) CI 95\% \\
Centre & $<0.01$ & 0.0379 & Adjustment factor \\
Age & 0.03 & & \\
BMI & $<0.001$ & & \\
Tobacco use & 0.003 & 0.0018 & $2.244[1.352-3.726]$ \\
Diabetes & 0.04 & & \\
Cancer & 0.06 & & \\
Corticosteroids & 0.1 & & \\
First implantation & 0.07 & & \\
Duration of surgery & 0.004 & & \\
Hematoma & 0.002 & 0.0026 & $4.665[1.714-12.695]$ \\
Nasal carriage of S. aureus & 0.3 & & \\
NNIS & $<0.001$ & $<0.0001$ & $3.073[1.874-5.038]$ \\
ASA score $>2$ & $<0.01$ & &
\end{tabular}

For SSI due to S.aureus

\begin{tabular}{lccc} 
Centre & NS & 0.9978 & Adjustment factor \\
ASA score $>2$ & $<0.01$ & & \\
BMI & 0.2 & & \\
Tobacco use & 0.005 & 0.0024 & $3.907[1.621-9.420]$ \\
Diabetes & 0.025 & & \\
Cancer & 0.02 & & \\
Duration of surgery & 0.02 & & \\
Nasal carriage of S. aureus & 0.02 & 0.0208 & $2.786[1.169-6.640]$ \\
NNIS & $<0.001$ & 0.0007 & $5.205[2.013-13.455]$ \\
\hline
\end{tabular}


Dear Editor,

Please find enclosed a revised manuscript of our study entitled "Is nasal carriage of Staphylococcus aureus the main acquisition pathway for surgical-site infection in orthopaedic surgery?" Ms. No. EJCMID-D-09-00479 and the answers, point by point, to the queries of the two reviewers that are detailed below. The main changes done are highlighted in yellow in one of the copy of the new manuscript.

We hope that this new version will be found suitable for publication in your journal. I look forward to hearing from you soon.

Sincerely yours,

Pr Berthelot

$\mathrm{MD}, \mathrm{PhD}$.

\section{Reply to reviewers}

Thank you for these interesting comments. Please find below our answers to the queries of the two reviewers.

\section{Reviewer 1}

It is unfortunate that they did not screen other sites such as the throat and perineum.

We agree with this comment. Initially, the protocol included a rectal swabbing but many patients were reluctant to this proposal. Due to a high rate of missing data during the initial step of the study, we decided to stop the sampling of this site. The following sentence was added in the discussion section of the new manuscript (page 11; lines 12 to 14): "Our protocol included initially a rectal swabbing before surgery; however, since many patients denied this sample, the data regarding rectal specimens could not be taken into consideration".

Concerning the throat sampling, when the study was designed in 2002, sampling this site was not recommended since this specimen was not considered at this time to increase significantly the sensitivity of the recovery of $S$. aureus from the upper respiratory tract as shown later by Metz et al. in 2007 [ref 23] (this point is discussed page 11, lines 14 to 17).

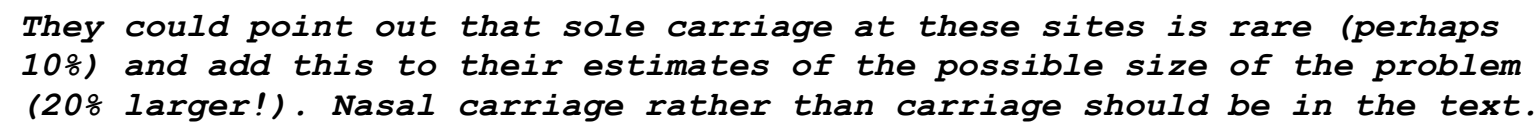

We also agree with this comment, which is emphasised in the new discussion section (page 11; lines 14 to 17): "With a single nasal sample and in the absence of additional throat and rectal specimens, the frequency of carriage of $S$. aureus in our cohort was certainly underestimated, as illustrated by the figure of $20.2 \%$ of nasal carriers in this study compared to $37.1 \%$ in the one of Mertz et al [23] that combined nasal and throat samplings." 
Comment 1 about CNS data:

1) Table 3 has overall data. They could compare the antibiograms of the individual isolates and see if there are very different strains. I doubt the organisms are available for molecular analysis (if so this could be "future work" for the discussion) but at least the antibiograms could be compared by ward and centre and see if there are any similarities and differences and informed guesses made as to the likelihood of cross infection e.g. quinolone resistance is usually mutational 2) All the other infected organism data. Again what about antibiograms and possible cross infection?

The goal of the study was to address the potential link between $S$. aureus nasal carriage and occurrence of $S$. aureus SSI, and not to study CNS or other bacterial cross infections. Strains other than $S$. aureus were not kept for further analysis. By contrast, the potentiality of cross infections with $S$. aureus was investigated and presented with some details in the revised manuscript (see below).

3) S aureus data.

We need to see their rule set for deciding why the extra 5 strains were different or similar. This is a difficult area and must be explained.

The way used to compare antibiotypes is reported in the method section (page 6, lines 12 to 16). As required by the referee, additional information regarding the comparison of antibiotic profiles has been added in the footnotes of Table III.

They should compare the 13 SA from non carriers (and indeed the carriers) to see if there are possible issues of cross infection in terms of time person and place of the affected patients. Are these strains similar by $P F G E$ ? Are they similar to any of the carriers?

From the 13 S. aureus SSI strains isolated from non nasal carriers, 8 were available for comparison by PFGE: all these strains exhibited independent profiles, also different from those of strains isolated from the nose of colonised patients. The 5 remaining strains were isolated from non nasal carriers hospitalized in 5 different centres, excluding cross transmission. These data were added in the result section page 9 lines 10 to 13 .

Table IV only has death related risk analysis not as stated on page 10 lines 23-24 for SSI and SA nasal carriage.

Because of the low number of SSI infections, the multivariate analysis was run with a maximum of 3 covariates selected among the most significant in the univariate analyses. This sentence was added in the method section (page 8 lines 8 to 10). We also modified the sentence presenting Table IV (page 10 lines 14 to 15 ).

4) There are also the therapeutic issues raised by the AST results for all categories of infections above. These are perhaps a little peripheral but I think it would add to the paper or perhaps be another one if there are clinical outcome data?

Data regarding therapeutic issues are not presented in this paper. Another clinical paper focusing on these results is in preparation 
Other points

How were nasal swabs taken: were the swabs moistened?

The precision regarding moistened transport medium was added in the method section (page 5 , line 1).

Was the PFGE protocol validated to be able to distinguish strains and how?

The criteria for PFGE interpretation are described page 6 lines 10 to 12 "For a same patient, according to Tenover's criteria [18], two $S$. aureus strains were classified as epidemiologically distinct if a difference of more than three bands was ascertained between the PFGE profiles performed in a same run”.

\section{Reviewer 2}

First this was a multicenter study and in these kind of studies cluster effects may occur. In the multivariate analysis, adjustment for cluster effects was not included. This would strengthen the conclusions.

As pointed by the reviewer it is important to look for cluster effect. This was investigated by adding a "centre" variable in the different statistical analyses. This variable did not remain in the final model used for multivariate analysis. But as required by the referee, we performed another multivariate analysis using windows SAS® 9.1 software to adjust for cluster effect. This was added in the method section (page 7, line 25). We replaced the results of the previous multivariate analysis performed using SPSS software by the results of this multivariate analysis adjusted for cluster effect (Table IV).

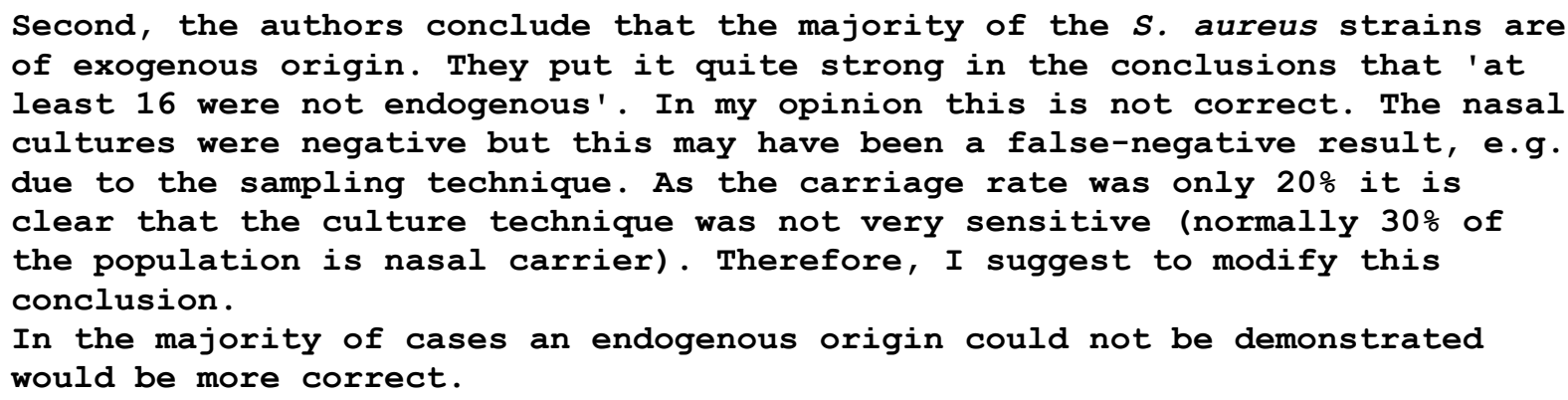

We agree with this comment. The discussion section was amended accordingly (see answer to reviewer 1 and additional sentence in page 11; lines 14 to 17)).

As suggested by the referee, we also modified the conclusion; the sentence "In most cases of S. aureus SSI, pre-operative nasal colonization was not documented or retrieved a different strain from the infecting pathogen" was replaced by the following one in the new manuscript (page 12, lines 20 to 22 and in the abstract): "In most cases of $S$. aureus SSI, either an endogenous origin could not be demonstrated, or pre-operative nasal colonisation retrieved a strain different from the one recovered from the surgical site" 
Also, it would be important to provide information on the typing of the strains from non-carriers as well. I wonder whether there were many similar strains within centers suggesting a common source?

This point was also addressed by reviewer 1 . No cross transmission of $S$. aureus was documented in this cohort. This important point was added in the result and discussion section, page 9 lines 10 to 13 . The following sentence was added page 12 line 11 to 12 "It is noteworthy that, in our study, no cross transmission of $S$. aureus within centres was documented". 